\title{
Effect of $\mathrm{Memo}^{\circledR}$, a natural formula combination, on Mini-Mental State Examination scores in patients with mild cognitive impairment
}

\author{
Mostafa Yakoot' \\ Amel Salem ${ }^{2}$ \\ Sherine Helmy ${ }^{3}$ \\ 'Green Clinic and Research \\ Center, ${ }^{2}$ Mabarrah Clinics, \\ ${ }^{3}$ Pharco Pharmaceutical \\ Industries, Alexandria, Egypt
}

Video abstract

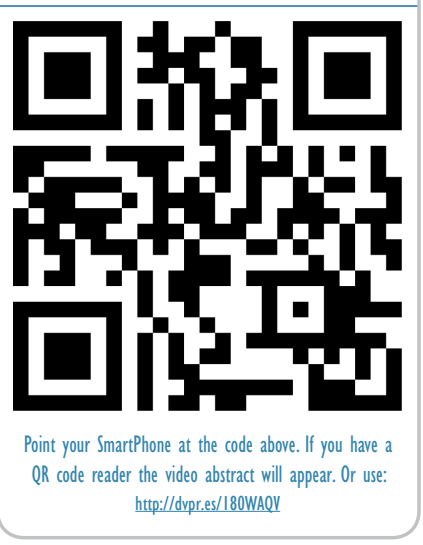

Correspondence: Mostafa Yakoot

27 Green Street 2I I I , Alexandria, Egypt

Tel +20 I2 2392756 I

Emailyakoot@yahoo.com
This article was published in the following Dove Press journal:

Clinical Interventions in Aging

23 July 2013

Number of times this article has been viewed

Background: Mild cognitive impairment encompasses the clinical continuum between physiologic age-related cognitive changes and dementia. A variety of medications, including herbal preparations (in particular Ginkgo biloba and Panax ginseng), have been advocated as treatments for cognitive impairment in the elderly. In this study, we investigated the effect of an already marketed dietary supplement $\left(\mathrm{Memo}^{\circledR}\right)$ combining $750 \mathrm{mg}$ of lyophilized royal jelly with standardized extracts of G. biloba $120 \mathrm{mg}$ and P. ginseng $150 \mathrm{mg}$ on Mini-Mental State Examination (MMSE) scores in patients with mild cognitive impairment.

Methods: Sixty-six subjects presenting with forgetfulness and satisfying the Diagnostic and Statistical Manual of Mental Disorders, 4th Edition, Text Revision (DSM-IV-TR) clinical criteria for mild cognitive impairment were randomly divided into an experimental group treated with one Memo capsule before breakfast daily for 4 weeks and a control group who took placebo. The mean change in MMSE score from baseline and reported adverse effects were compared between the two groups.

Results: The mean change in MMSE score in the group treated with Memo for 4 weeks was significantly greater than in the control group $(+2.07$ versus +0.13 , respectively) by the Student's $t$-test $(t=6.485, P<0.0001)$. This was also true after adjusting for age as a covariate and educational level as a factor nested within the treatment groups in a general linear model (analysis of covariance, $F=9.675$ [corrected model], $P<0.0001$ ).

Conclusion: This combined triple formula may be beneficial in treating the cognitive decline that occurs during the aging process as well as in the early phases of pathologic cognitive impairment typical of insidious-onset vascular dementia and in the early stages of Alzheimer's disease. Larger-sized studies with longer treatment durations are needed to confirm this.

Keywords: mild cognitive impairment, Alzheimer's disease, vascular dementia, Mini-Mental State Examination

\section{Introduction}

Mild cognitive impairment (MCI) encompasses the clinical continuum between physiologic age-related cognitive changes and dementia. Alzheimer's disease and vascular dementia are the most prevalent dementias among the elderly. Vascular dementia has a more heterogeneous origin, pathogenesis, and clinical course compared with Alzheimer's disease..$^{1-3}$ According to the speed of onset of dementia, vascular dementia can be separated into two groups, ie, one with abrupt onset caused predominantly by multi-infarct, strategic infarct, or intracranial hemorrhage, and the other with insidious onset, caused predominantly by subcortical, lacunar, small vessel disease. ${ }^{4,5}$ The proportion of insidious-onset dementia attributable to subcortical small 
vessel disease ranges from $36 \%$ to $67 \%$ according to different authors and is higher among nonwhite individuals. ${ }^{6-8}$

Early identification of Alzheimer's disease and insidiousonset vascular dementia during the prodromal manifestations of mild cognitive impairment shared by both conditions introduces an opportunity for clinical intervention that may hopefully arrest or even reverse cognitive deterioration. ${ }^{9-11}$ During these early predementia stages of mild cognitive impairment, it is difficult to differentiate between vascular dementia and Alzheimer's disease utilizing the widely used Mini-Mental State Examination (MMSE). ${ }^{12}$

Thus far, guideline-based drug therapy for cognitive impairment in dementia consists of two classes, ie, the cholinesterase inhibitors (donepezil, galantamine, rivastigmine, tacrine) and an N-methyl-D-aspartate antagonist (memantine). Physicians, especially in developing countries, have faced difficulties in prescribing guideline-based drug therapy in real-life practice because of the high cost of these drugs as well as their frequent adverse effects, weak efficacy in moderate and severe cases, and rapid reversal of efficacy after their withdrawal. ${ }^{13}$

A variety of other lower-cost medications, including nonsteroidal anti-inflammatory drugs, hormones (particularly estrogen), vitamins (eg, vitamin E) and herbal preparations (eg, Ginkgo biloba and Panax ginseng) have been advocated as treatments for memory loss in the elderly, but clinical evidence for their efficacy is still inconclusive .

Numerous studies have shown that G. biloba has antioxidant and free radical scavenging, ${ }^{14-17}$ neuroprotective, ${ }^{18,19}$ and antiplatelet effects. ${ }^{20}$ Beneficial actions of the plant extract in ischemia-reperfusion injury, ${ }^{14}$ hypoxia, ${ }^{16}$ cerebrovascular disease, ${ }^{21}$ and cognitive deficits and dementia ${ }^{22-24}$ have also been described.

Extract of $G$. biloba has been shown to improve fluidity and decrease deformability of neuronal membranes, that may be altered in aging and several pathologic conditions. ${ }^{23-25}$ It has also been found to increase the density of muscarinic, cholinergic, adrenergic, and brain dopaminergic transmission. ${ }^{26}$ Further, G. biloba has been found to be able to increase the rate of acetylcholine turnover and to stimulate binding activity of ligands at the muscarinic receptors in the hippocampus. ${ }^{27}$

Several human and animal studies showed better abstract thinking and improved mental abilities, stamina, and endurance when using $P$. ginseng. ${ }^{28,29}$

Royal jelly is well known for its high nutritional value. It is rich in substances of high biological and health-promoting values, like sterols, phosphorous compounds, important fatty acids, and acetylcholine. Royal jelly has been suggested to facilitate differentiation of several types of brain cells (neurons, astrocytes, and oligodendrocytes) via its content of many bioactive components that can differently influence neuronal and/or glial cell lineages. ${ }^{30}$ Royal jelly and its unique fatty acid, 10-hydroxy-trans-2-decenoic acid, has been found recently to promote neurogenesis of neural stem/progenitor cells in vitro. ${ }^{30}$

Adenosine monophosphate (AMP) N1-oxide, a unique compound of royal jelly, was also found to induce proliferation and/or differentiation of cultured neural stem/ progenitor cells and to facilitate astrogenesis via many mechanisms, including activation of signal transducer and activator of transcription 3 and stimulation of phosphorylation, not only of mitogen-activated protein kinase but also of cAMP/calcium-response element-binding protein in a dosedependent manner. ${ }^{31,32}$ Orally administered royal jelly was found to increase the number of hippocampal dentate gyrus granule cells significantly and to improve cognitive impairment in trimethyltin-intoxicated mice. ${ }^{33}$ Based on the above data suggestive of benefit of these safe and long-used nutritional substances, we hypothesized that a combination of the three substances, ie, G. biloba, P. ginseng, and royal jelly, through summation of many additive and complementary mechanisms, could provide cognitive benefits in an exploratory, randomized, controlled study that could support the inconclusive evidence or encourage further larger studies.

Memo $^{\circledR}$ is a dietary supplement produced by Pharco Pharmaceuticals, Alexandria, Egypt, and is marketed in the form of soft gelatin capsules, combining lyophilized royal jelly $750 \mathrm{mg}$ and standardized extracts of G. biloba $120 \mathrm{mg}$ and $P$. ginseng $150 \mathrm{mg}$. We planned this pilot study to explore the effect of this triple natural formula on MMSE scores in patients with mild cognitive impairment.

\section{Materials and methods}

This clinical trial was conducted in two clinics in Alexandria, Egypt, according to a randomized, double-blind, placebocontrolled study design in an outpatient setting.

\section{Sample size}

Group sample sizes of 26 each were precalculated to achieve $81 \%$ power to detect a mean difference of two points in change from baseline MMSE score between the two treatment groups with estimated group standard deviations of 2.5 and an alpha significance level of 0.05 using a twosided two-samples $t$-test. The study included 60 patients for final analysis, ie, 30 patients for each randomly assigned 
treatment group. Recruitment of patients in the outpatient clinics started from April 2006 and ended by February 2008, on the basis of the following selection criteria.

\section{Inclusion criteria}

Male or female patients, aged 50-80 years, complaining of memory impairment or forgetfulness and satisfying the clinical criteria for mild cognitive impairment in the
Diagnostic and Statistical Manual of Mental Disorders Fourth Edition, Text Revision, (DSM-IV-TR) including memory complaint, normal activities of daily living, abnormal memory for age, and no documented dementia. ${ }^{34}$

\section{Exclusion criteria}

Exclusion criteria included an established diagnosis of dementia or a baseline MMSE score below 21, current

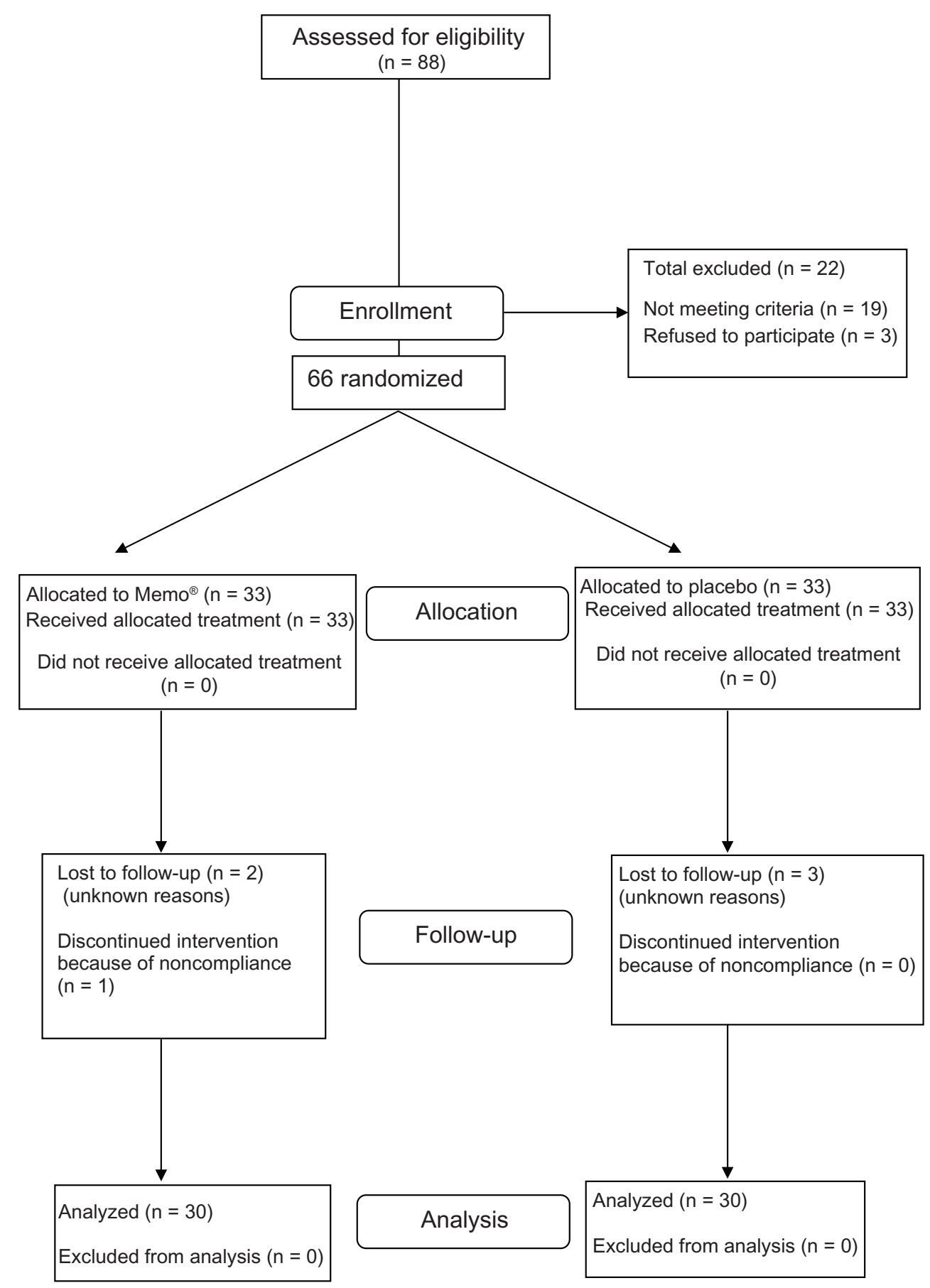

Figure I Patient flowchart. 
treatment for dementia with any drug, herbal, or nutritional supplement, except patients with only mild cognitive impairment who stopped treatment for at least 1 month before enrollment; or a recent history or current treatment for any specific acute acquired brain injury, such as traumatic brain injury, acute onset stroke, or other acute medical condition. Patients with a history or current treatment for major depressive or psychotic illnesses, critically ill patients or those with severe anemia or vital organ dysfunction (ie, hepatic, renal, or cardiac failure) were also excluded.

\section{Interventions}

The study followed the guidelines of the Declaration of Helsinki and Tokyo for human research.

The protocol was approved by the local research ethics committee (IORG0006902, Green Clinic and Research Center institutional review board \#1) before starting any intervention.

Starting from April 2006, 88 consecutive patients presenting to the clinics with memory or cognitive decline were screened for eligibility. Eligible subjects fulfilling the inclusion/exclusion criteria were recruited and asked to sign informed consents. Those who voluntarily agreed to be enrolled in the study and signed their consent were randomly divided into two groups, ie, an experimental group which started 4 weeks of treatment with Memo soft gelatin capsules at a dose of one capsule daily before breakfast and a control group who took placebo in the same daily dose for the same period.

\section{Medications}

Memo was supplied free of charge for this study along with similar inert-substance filled capsules in similar packs to be used as the placebo. Each soft gelatin capsule of Memo combines $750 \mathrm{mg}$ of natural lyophilized royal jelly (standardized to at least $6 \%$ of 10-hydroxy-2-decenoic acid) with two standardized herbal extracts, ie, G. biloba leaf extract $120 \mathrm{mg}$ (standardized to contain 24\% flavonoid glycosides and $6 \%$ terpenoids) and $150 \mathrm{mg}$ of $P$. ginseng alcohol root extract (containing 40\%-80\% ginsenosides).

\section{Randomization and blinding}

A block randomization technique was used to ensure equal numbers in the treatment groups. Each patient received a coded bottle containing 35 capsules of either the test drug or placebo. Both patients and physicians were blinded to treatment allocation by having the bottles coded by a company statistician who kept the codes for patient allocation in sealed opaque envelopes in a safe place and was not involved further in this research, except for decoding the data at the end of the study. All subjects were asked to revisit the same treating doctor in the same clinic in the event of a serious adverse event or every 2 weeks for follow-up of compliance by counting the remaining capsules and reporting of any adverse effects or unintended positive effects.

\section{Outcome measures and statistical analysis}

We used the MMSE as the most widely recognized and simplest instrument for detection of cognitive impairment ${ }^{35}$ (Appendix 1). At baseline, all patients were examined both physically and neuropsychologically for eligibility. Each patient underwent an MMSE with verbal assistance from the same examiner at baseline and after 4 weeks of treatment. Patients with MMSE scores below 21 at baseline were excluded.

MMSE scores at baseline and after 4 weeks of treatment were compared in both treatment groups using the pairedsamples $t$-test. Mean changes in MMSE from baseline were compared between the treatment groups after 4 weeks of treatment using the Student's $t$-test for independent samples as well as a general linear model (analysis of covariance)

Table I Baseline characteristics in the treatment groups

\begin{tabular}{lllll}
\hline Baseline variable & $\begin{array}{l}\text { Experimental group } \\
(\mathbf{n}=\mathbf{3 0})\end{array}$ & $\begin{array}{l}\text { Control group } \\
(\mathbf{n = 3 0 )}\end{array}$ & Test & Significance \\
\hline Age, years (mean \pm SD) & $65.97 \pm 6.52$ & $66.43 \pm 5.79$ & t-test & 0.771 \\
Male to female ratio & $19 / 11$ & $14 / 16$ & Chi-square & 0.299 \\
MMSE score (mean \pm SD) & $24.90 \pm 1.06$ & $24.87 \pm 1.14$ & t-test & 0.907 \\
Education level & & & & \\
$\quad$ Primary/preparatory & 10 & 9 & Z-test for & 0.779 \\
$\quad$ Secondary & 9 & 14 & proportions & 0.184 \\
$\quad$ University & 11 & 7 & & 0.258 \\
\hline
\end{tabular}

Abbreviations: MMSE, Mini-Mental State Examination; SD, standard deviation; n, number. 
Table 2 Paired statistics for mean MMSE scores before treatment and after 4 weeks

\begin{tabular}{lcccc}
\hline Treatment group & Mean & SD & t-test & Significance \\
\hline $\begin{array}{l}\text { Memo }^{\circledR} \\
\text { Pair }\end{array}$ & & & & \\
$\quad$ Baseline MMSE & 24.90 & 1.06 & -9.90 & $<0.000 \mathrm{I}$ \\
$\quad$ MMSE end of 4 weeks & 26.97 & 1.38 & & \\
$\begin{array}{l}\text { Placebo } \\
\text { Pair }\end{array}$ & & & & \\
$\quad$ Baseline MMSE & 24.87 & 1.14 & -0.626 & 0.536 \\
$\quad$ MMSE end of 4 weeks & 25.00 & 1.41 & & \\
\hline
\end{tabular}

Abbreviations: MMSE, Mini-Mental State Examination; SD, standard deviation.

adjusting for the effect of age as a covariate and educational level as a nested factor within treatment groups.

The effect of gender as an independent variable on the mean change in MMSE from baseline after 4 weeks of treatment was tested by one-way analysis of variance. Any reported serious and nonserious adverse events were included in the patient record for comparison. The data were analyzed using Statistical Package for the Social Sciences version 17.0 software (SPSS Inc, Chicago, IL, USA).

\section{Results}

Of 88 patients presenting with forgetfulness and screened, a total of 69 were found to be eligible for the study according to the inclusion and exclusion criteria. Three patients refused to be included and did not sign their informed consent. The remaining 66 patients were randomly assigned in equal number to the treatment groups. Of the 33 patients assigned to each group, two from the experimental group and three from the control group dropped out during follow-up for unknown reasons. Another subject from the experimental group was excluded because of poor compliance discovered on counting of the remaining capsules. All the remaining participants who completed the study protocol were included in the final analysis (Figure 1). At baseline, both groups were found to be well matched for demographic characteristics and baseline MMSE scores (Table 1).

Table 3 Comparison of the mean difference in MMSE scores between treatment groups

\begin{tabular}{llllll}
\hline Group & $\mathbf{n}$ & $\begin{array}{l}\text { Change in mean } \\
\text { MMSE score } \\
\text { from baseline }\end{array}$ & SD & t-test & Significance \\
\hline Memo $^{\circledR}$ & 30 & 2.067 & 1.143 & 6.485 & $<0.000 \mathrm{I}$ \\
Placebo $^{30}$ & 0.133 & 1.167 & & \\
\hline
\end{tabular}

Abbreviations: MMSE, Mini-Mental State Examination; SD, standard deviation.
There was a statistically significant improvement in MMSE score by paired-samples $t$-test after 4 weeks of treatment only in the group treated with Memo (Table 2). The mean change in MMSE score in the group treated with Memo for 4 weeks was significantly better than in the control group $(+2.067$ versus +0.133 , respectively) using the Student's $t$-test for independent samples $(t=6.485, P<0.0001$, Table 3 and Figure 2). This remained true after adjusting for age as a covariate and educational level as a factor nested within the treatment groups in a general linear model (analysis of covariance, $F=9.675$ [corrected model], $P<0.0001$, Table 4). One-way analysis of variance showed no significant effect of gender $(F=0.003, P=0.959)$ on the main outcome variable, ie, a difference in MMSE from baseline (Figure 2).

No serious adverse events were reported in either group, with only mild nausea and dyspeptic symptoms reported in three subjects in each group, and mild transient headache in three subjects in the Memo group and two subjects in the control group $(P>0.05)$. A mild subjective sense of flushing and palpitation during the first 3 days of treatment was reported by five patients in the Memo group and by three patients in the control group $(P>0.05)$. Improved sexual performance and libido were reported by men treated with Memo, but this did not reach statistical significance $(P>0.05)$.

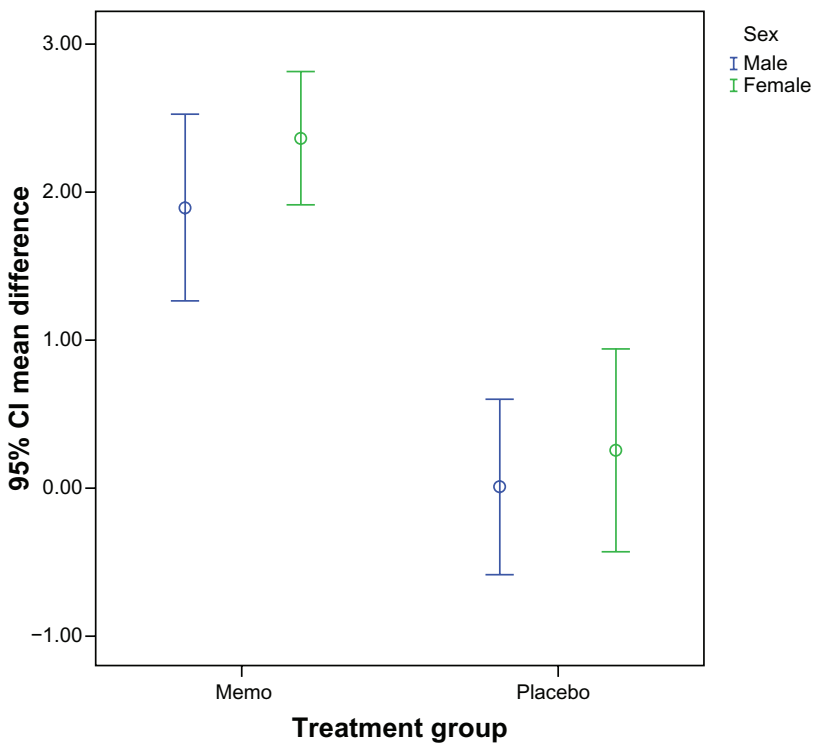

Figure 2 Significantly superior effect of 4 weeks of treatment with $\mathrm{Memo}^{\circledR}$ on the MMSE score in men and women. There was no significant effect of gender on the outcome measure.

Abbreviations: $\mathrm{Cl}$, confidence interval; MMSE, Mini-Mental State Examination. 
Table 4 General linear model analysis of covariance (ANCOVA) for the treatment effect corrected for age and education level within treatment groups

\begin{tabular}{|c|c|c|c|c|c|}
\hline Source & $\begin{array}{l}\text { Type III sum } \\
\text { of squares }\end{array}$ & & $\begin{array}{l}\text { Mean } \\
\text { square }\end{array}$ & $\boldsymbol{F}$ & Significance \\
\hline \multicolumn{6}{|c|}{ Dependent variable: mean change in MMSE scores from baseline } \\
\hline Corrected model & $69.733^{\mathrm{a}}$ & 6 & 11.622 & 9.675 & 0.000 \\
\hline Intercept & 8.054 & I & 8.054 & 6.705 & 0.012 \\
\hline Age & 4.536 & I & 4.536 & 3.776 & 0.057 \\
\hline $\begin{array}{l}\text { Education } \\
\text { (treatment) }\end{array}$ & 10.103 & 4 & 2.526 & 2.103 & 0.093 \\
\hline Treatment & 53.743 & I & 53.743 & 44.739 & 0.000 \\
\hline Error & 63.667 & 53 & 1.201 & & \\
\hline Total & 206.000 & 60 & & & \\
\hline Corrected total & 133.400 & 59 & & & \\
\hline
\end{tabular}

Note: ${ }^{a} R^{2}=0.523$ (adjusted $R^{2}=0.469$ )

Abbreviation: $\mathrm{df}$, degrees of freedom.

\section{Discussion}

Our results showed a significantly better effect of Memo on the MMSE score than placebo after 4 weeks of treatment. Many investigators had demonstrated the cognitionenhancing effects of $G$. biloba and $P$. ginseng used alone or together in human subjects. ${ }^{22,24,28,36,37}$ However, there have been very few studies investigating the effect of royal jelly on mental or cognitive health in humans. Morita et al studied the effects of 6 months of royal jelly in healthy volunteers and reported a significant effect of royal jelly versus placebo on the mental health subscales of the Short Form-36. ${ }^{38}$ To our knowledge, the theoretically anticipated therapeutic benefits of adding royal jelly, with its neurotonic and neurogenesispromoting properties, to a G. biloba-P. ginseng combination have not been clinically studied before, and this clinical trial may be the earliest to indicate the efficacy of this natural triple combination in patients with mild cognitive impairment.

We acknowledge several limitations to our study arising from financial constraints. These include its short duration of follow-up, the use of MMSE scores alone for inclusion in the study and for measuring outcome without using other comprehensive investigative or imaging procedures.

\section{Conclusion}

From our results, we conclude that this triple combination of natural products may be beneficial in the treatment of cognitive decline occurring during the aging process as well as in the early phases of pathologic cognitive impairment that typically occur in insidious-onset vascular dementia and the early stages of Alzheimer's disease. Larger-sized studies of longer duration are needed to confirm our findings.

\section{Acknowledgment}

The authors acknowledge the sincere help and support of Medhat Kassem and Mohsen Omar from Pharco Pharmaceutical Industries, who had a major role in preparation and coding of the drug packs and concealment of treatment allocation.

\section{Author contributions}

MY conceived the study, formulated the research question, and participated in its design, coordination, and conduct. He took an active part throughout the study process from patient screening to final assessment, the statistical analysis, and manuscript writing. AS shared in all the steps from screening of patients to manuscript writing and approval. $\mathrm{SH}$ managed the formulation, analysis, and quality control of the drug formulation and shared in writing and final approval of the manuscript.

\section{Disclosure}

Pharco Pharmaceutical Industries supplied similarly coded packages containing either Memo capsules or placebo capsules of identical appearance free of charge. The authors report no other conflicts of interest in this work.

\section{References}

1. Rockwood K, Bowler J, Erkinjuntti T, Hachinski V, Wallin A. Subtypes of vascular dementia. Alzheimer Dis Assoc Disord. 1999;13 Suppl 3: S59-S65.

2. Loeb C, Meyer JS. Vascular dementia: still a debatable entity? J Neurol Sci. 1996;143:31-40.

3. Erkinjuntti T. Vascular dementia: an overview. In: O'Brien J, Bruns L, editors. Dementia, 2nd ed. London, UK: Arnold Press; 2000.

4. Erkinjuntti T, Inzitari D, Pantoni L, et al. Research criteria for subcortical vascular dementia in clinical trials. J Neural Transm Suppl. 2000;59:23-30

5. Chui H. Dementia due to subcortical ischemic vascular disease. Clin Cornerstone. 2001;3:40-51

6. Erkinjuntti T. Types of multi-infarct dementia. Acta Neurol Scand. 1987;75:391-399

7. Cummings JL. Vascular subcortical dementias: clinical aspects. Dementia. 1994;5:177-180.

8. Brun A. Pathology and pathophysiology of cerebrovascular dementia: pure subgroups of obstructive and hypoperfusive etiology. Dementia. 1994;5:145-147.

9. Skoog I. Status of risk factors for vascular dementia. Neuroepidemiology. 1998; 17:2-9.

10. Meyer JS, Rogers RL, McClintic K, Mortel KF, Lotfi J. Randomized clinical trial of daily aspirin therapy in multi-infarct dementia: a pilot study. J Am Geriatr Soc. 1989;37:549-555.

11. Li Y, Meyer JS, Haque MA, Chowdhury MH, Hinh P, Quach M. Feasibility of vascular dementia treatment with cholinesterase inhibitors. Int J Geriatr Psychiatry. 2002;17:194-196.

12. Meyer JS, Xu G, Thornby J, Chowdhury MH, Quach M. Is mild cognitive impairment prodromal for vascular dementia like Alzheimer's disease? Stroke. 2002;33:1981-1985. 
13. Wollen KA. Alzheimer's disease: the pros and cons of pharmaceutical, nutritional, botanical, and stimulatory therapies, with a discussion of treatment strategies from the perspective of patients and practitioners. Altern Med Rev. 2010;15:223-244.

14. Guidetti C, Paracchini S, Lucchini S, Cambieri M, Marzatico F. Prevention of neuronal cell damage induced by oxidative stress in vitro: effect of different Ginkgo biloba extracts. J Pharm Pharmacol. 2001;53:387-392.

15. Oyama Y, Fuchs PA, Katayama N, Noda K. Myricetin and quercetin, the flavonoid constituents of Ginkgo biloba extract, greatly reduce oxidative metabolism in both resting and Ca-loaded brain neurons. Brain Res. 1994;635:125-129.

16. Tendi EA, Bosetti F, Dasgupta SF, Stella AM, Drieu K, Rapoport SI. Ginkgo biloba extracts EGB 761 and bilobalide increase NADH dehydrogenase mRNA level and mitochondrial respiratory control ratio in PC12 cells. Neurochem Res. 2002;27:319-329.

17. Rapin JR, Lamproglou I, Drieu K, DeFeudis FV. Demonstration of the anti-stress activity of an extract of Ginkgo biloba (EGB 761) using a discrimination learning task. Gen Pharmacol. 1994;25: 1009-1016.

18. NiY, Zhao B, Hou J, Xin W. Preventive effect of Ginkgo biloba extract on apoptosis in rat cerebellar neuronal cells induced by hydroxyl radicals. Neurosci Lett. 1996;214:115-118.

19. Porsolt RD, Martin P, Lenègre A, Fromage S, Drieu K. Effects of an extract of Ginkgo biloba (EGB 761) on "learned helplessness" and other models of stress in rodents. Pharmacol Biochem Behav. 1990;36: 963-971.

20. Smith PF, Maclennan L, Darlington CL. The neuroprotective properties of the Ginkgo biloba leaf: a review of the possible relationship to platelet activating factor (PAF). J Ethnopharmacol. 1996;50:131-139.

21. Clostre F. [Ginkgo biloba extract (EGb 761). State of knowledge in the dawn of the year 2000]. Ann Pharm Fr. 1999;57 Suppl 1:1S8-S88. French.

22. Curtis-Prior P, Vere D, Fray P. Therapeutic value of Ginkgo biloba in reducing symptoms of decline in mental function. J Pharm Pharmacol. 1999;51:535-541

23. Hoyer S, Lannert H, Nöldner M, Chatterjee SS. Damaged neuronal energy metabolism and behavior are improved by Ginkgo biloba extract (EGb 761). J Neural Transm. 1999;106:1171-1188.

24. Kanowski S, Herrmann WM, Stephan K, Wierich W, Hörr R. Proof of efficacy of the Ginkgo biloba special extract EGb 761 in outpatients suffering from mild to moderate primary degenerative dementia of the Alzheimer type or multi-infarct dementia. Pharmacopsychiatry. 1996;29:47-56.
25. Ramassamy C, Naudin B, Christen Y, et al. Ginkgo biloba extract EGB 761 or Trolax C prevent ascorbic acid/Fe-induced decrease in synaptasomal membrane fluidity. Free Radical Res. 1993;19: 395-4401.

26. Muller WE. Nootropics, the therapy of dementia between aspiration and reality. Drug News Perspect. 1989;2:295-300.

27. Itil T, Martorano D. Natural substances in psychiatry (Ginkgo biloba in dementia). Psychopharmacol Bull. 1995;31:147-158.

28. Sorensen H, Sonne J. A double-masked study of the effects of ginseng on cognitive functions. Curr Ther Res. 1996;57:959-968.

29. Ni X-H, Ohta H, Watanabe H, Mastsumoto K. Panax ginseng extract improves scopolamine-induced deficits in working memory performance in the T-maze delayed alternation task in rats. Phytother Res. 1993; 7:49-52.

30. Hattori N, Nomoto H, Fukumitsu H, Mishima S, Furukawa S. Royal jelly and its unique fatty acid, 10-hydroxy-trans-2-decenoic acid, promote neurogenesis by neural stem/progenitor cells in vitro. Biomed Res. 2007;5:261-266.

31. Hattori N, Nomoto H, Fukumitsu H, Mishima S, Furukawa S. AMP N1-oxide potentiates astrogenesis by cultured neural stem/progenitor cells through STAT3 activation. Biomed Res. 2008;6:295-299.

32. Hattori N, Nomoto H, Fukumitsu H, Mishima S, Furukawa S. AMP $\mathrm{N}(1)$-oxide, a unique compound of royal jelly, induces neurite outgrowth from PC12 cells via signaling by protein kinase A independent of that by mitogen-activated protein kinase. Evid Based Complement Alternat Med. 2010;7:63-68.

33. Hattori N, Ohta S, Sakamoto T, Mishima S, Furukawa S. Royal jelly facilitates restoration of the cognitive ability in trimethyltin-intoxicated mice. Evid Based Complement Alternat Med. 2011;2011:165968.

34. American Psychiatric Association. Diagnostic and Statistical Manual of Mental Disorders, 4th ed. Washington, DC: American Psychiatric Association; 1994

35. Folstein MF, Folstein SE, McHugh PR. Mini-Mental State. A practical method for grading the cognitive state of patients for the clinician. J Psychiatr Res. 1975;12:189-198.

36. Wesnes KA, Ward T, Petrini O, McGinty A. The memory enhancing effects of a Ginkgo biloba/Panax ginseng combination in healthy middle aged volunteers. Psychopharmacology. 2000;152:353-336.

37. Kennedy DO, Scholey AB, Wesnes KA. Modulation of cognition and mood following administration of single doses of Ginkgo biloba, ginseng, and a ginkgo/ginseng combination to healthy young adults. Physiol Behav. 2002;75:739-751.

38. Morita H, Ikeda T, Kajita K, et al. Effect of royal jelly ingestion for six months on healthy volunteers. Nutr J. 2012;11:77.
Clinical Interventions in Aging

\section{Publish your work in this journal}

Clinical Interventions in Aging is an international, peer-reviewed journal focusing on evidence-based reports on the value or lack thereof of treatments intended to prevent or delay the onset of maladaptive correlates of aging in human beings. This journal is indexed on PubMed Central, MedLine, the American Chemical Society's 'Chemical Abstracts

\section{Dovepress}

Service' (CAS), Scopus and the Elsevier Bibliographic databases. The manuscript management system is completely online and includes a very quick and fair peer-review system, which is all easy to use. Visit http://www.dovepress.com/testimonials.php to read real quotes from published authors. 